\title{
Uso público em unidades de conservação: fragilidades e oportunidades para o turismo na utilização dos serviços ecossistêmicos
}

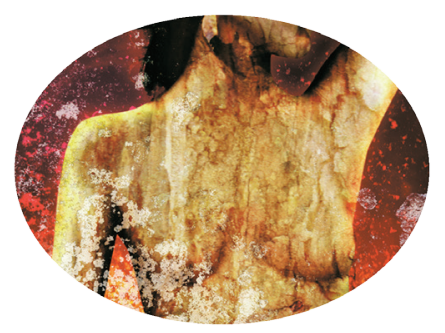

Susy Rodrigues Simonetti* Elimar Pinbeiro do Nascimento**

\section{Resumo}

O artigo discute as fragilidades e oportunidades para o turismo na exploração das belezas naturais em Unidades de Conservação, um promissor mercado voltado à valoração dos serviços ecossistêmicos. A criação e implementação de Unidades de Conservação, especificamente na Amazônia, têm se mostrado uma ferramenta efetiva nas políticas ambientais contribuindo para a gestão ambiental do território e protegendo os patrimônios cultural e natural. Após mais de uma década da implementação da Lei n. ${ }^{\circ}$ 9.985, que instituiu o Sistema Nacional de Unidades de Conservação da Natureza (SNUC), percebese um crescimento expressivo da visitação em áreas naturais no Brasil, com destaque para as atividades de turismo. Para compreender as oportunidades e as fragilidades no desenvolvimento do turismo, utilizaram-se categorias de análise reconhecidas por seus estudiosos. O uso público, incluindo a visitação turística, é uma estratégia oportuna que pode ser mais estimulada para potencializar os benefícios do turismo. No entanto, são muitos os desafios a serem superados, entre eles a proteção das espécies, a destinação dos resíduos,

\footnotetext{
" Doutoranda do PPGCASA, bolsista da Fapeam. Professora do Curso de Turismo da Universidade do Estado do Amazonas. E-mail: susyrsimonetti@bol.com.br
**: Sociólogo, com doutorado pela Universite de Paris V (Rene Descartes, 1982), professor associado na Universidade de Brasília, lotado no Centro de Desenvolvimento Sustentável (CDS) da UNB. E-mail: elimarcds@gmail.com


o desenvolvimento de atividades produtivas e de inclusão social, sobretudo no entorno das áreas protegidas. No intuito de garantir que os recursos ambientais das Unidades de Conservação sejam conservados, que as pessoas que habitam nessas áreas tenham suas atividades e cultura resguardadas e, ainda, para possibilitar que o visitante tenha uma experiência de boa qualidade, tornase necessário o planejamento e a gestão dessas áreas naturais, assim como a adoção de mecanismos como o pagamento por serviços ecossistêmicos. Ademais, para que o turismo seja menos impactante possível e se configure como um elemento capaz de contribuir para o desenvolvimento local e para a resiliência dos ecossistemas, é necessário pensar na sua ecologização.

Palavras-chave: (eco)turismo; áreas protegidas; serviços ecossistêmicos; ecologização do turismo.

\section{Abstract}

This article discusses the weaknesses and opportunities for tourism in the exploitation of the natural beauties in Units of Conservation (protected areas), a promising market facing the ecosystem services valuation. The creation and implementation of Units of Conservation, specifically in the Amazon, has shown to be an effective tool in environmental policies, contributing to a territory environmental management and protecting the cultural and natural heritage. After over a decade from the implementation of Law 9.985 which instituted the National System of Units of Conservation (SNUC), one sees an expressive growth in the number of visits to natural areas in Brazil, with emphasis on tourism activities. In order to comprehend the opportunities and weaknesses in the tourism development, analysis categories recognized by their scholars have been used. The public use, including touristic visitation, is a timely strategy that may be more stimulated, in order to potentiate the benefits of tourism. However, there are many challenges to overcome, among them, there are: the protection of species, waste allocation, development of productive activities and social inclusion, specially around the protected areas. In order to guarantee the conservation of the environment resources in the Units of Conservation, and that the people who live in these areas have their activities and culture safeguarded and, also, to enable the visitor to have a good-quality experience, it is necessary the planning and management of 
such natural areas, as well as the adoption of mechanisms such as payment of ecosystem services. After all, for tourism to be as less impactful as possible and can be set as an element capable of contributing to a local development and to the resilience of ecosystems, it is necessary to think about its greening.

Keywords: (eco) tourism; protected areas; ecosystem services; tourism greening.

\section{Introdução}

No dia 18 de julho de 2000, o Brasil aprovou a Lei n. 9.985, que instituiu o Sistema Nacional de Unidades de Conservação da Natureza (SNUC), visando ordenar a gestão territorial por meio da criação e implementação de áreas protegidas. $\mathrm{O}$ documento sinaliza que alguns desses espaços podem e devem receber visitantes, ou seja, o turismo é incentivado. Por outro lado, objetiva a conservação de seus recursos socioambientais.

Após mais de uma década de implementação da lei, percebe-se um crescimento expressivo da visitação em áreas naturais no Brasil, com destaque para as atividades de turismo como um segmento promissor nesses ambientes. Assim, houve a necessidade de planejar a visitação para que se possam cumprir os objetivos de criação de tais áreas.

Contudo, nada é muito fácil ou simples em se tratando do processo de criação, implementação e gestão das Unidades de Conservação (UCs) no território brasileiro. Dentre os obstáculos podem-se citar: restrição ao uso de parte das categorias instituídas, seja por falta de infraestrutura adequada ou mesmo impedimento legal; a falta de recursos para pagamento de indenizações ou para a manutenção das UCs; áreas naturais que possuem moradores e que por lei não é permitido. Além disso, a inexistência de planos de manejo; a desinformação sobre a importância desses espaços; a baixa capacidade de acompanhamento e controle da visitação impedem que de fato essas áreas cumpram seus objetivos.

Com o objetivo de garantir que os recursos ambientais das UCs sejam conservados, que as pessoas que habitam nessas áreas tenham suas atividades e cultura resguardadas e, no intuito de garantir ainda que o visitante tenha uma experiência de boa qualidade, tornam-se necessário o planejamento e a 
gestão dessas áreas naturais, favorecendo o desenvolvimento de um turismo sustentável.

Nesse sentido, incluir os benefícios não materiais dos ecossistemas, ou seja, os serviços culturais de recreação (turismo), de inspiração espiritual e saúde mental são extremamente válidos na relação turismo e áreas protegidas, entendendo que a capacidade dos ecossistemas geram serviços essenciais à vida dos seres humanos no planeta. Afinal, os ecossistemas são sistemas que englobam as complexas, dinâmicas e contínuas interações entre seres vivos e não vivos em seus ambientes físicos e biológicos, nos quais o homem é parte integral (MA, 2003).

Os serviços gerados pelos ecossistemas podem ser definidos da seguinte forma: serviços de provisão são os materiais que os ecossistemas fornecem como alimento, água e matérias-primas; serviços de regulação são aqueles fornecidos por ecossistemas ao agir como reguladores, tais como regular a qualidade do ar e do solo ou controlar enchentes e doenças; serviços de habitat ou suporte são subjacentes a quase todos os outros serviços, fornecem espaço para plantas e animais habitarem, sem contar que mantêm a diversidade de espécies de plantas e animais; por fim, estão os serviços culturais, que incluem os benefícios não materiais dos ecossistemas, de recreação à inspiração espiritual e saúde mental (TEEB, 2010). Neste último, o turismo tem um vasto campo para se desenvolver.

\section{O SNUC, o uso público e os serviços ecossistêmicos}

O conceito moderno de áreas protegidas surgiu com a criação do Parque Nacional Yellowstone, nos Estados Unidos, em 1872. Os objetivos que levaram à criação desse parque foram: a preservação de atributos cênicos, a significação histórica e o potencial para atividades de lazer. Embora, não custa alertar, a noção de parque norte-americana e a brasileira seja bem distinta.

No Brasil, a primeira iniciativa para a criação de uma área protegida ocorreu em 1876, como sugestão do engenheiro André Rebouças (inspirado na criação do Parque Yellowstone) de se criar dois parques nacionais: um em Sete Quedas e outro na Ilha do Bananal. No entanto, data de 1937 a criação do primeiro parque nacional brasileiro: o Parque Nacional de Itatiaia, no Rio de Janeiro (COSTA, 2002). 
O conjunto das Unidades de Conservação (UCs) do Brasil constitui o Sistema Nacional de Unidades de Conservação (SNUC), aprovado depois de quase dez anos tramitando no Congresso Nacional, com várias emendas e modificações: Lei n. ${ }^{\circ}$ 9.985, de 18 de julho de 2000. O SNUC, em seu artigo 2. define oficialmente Unidade de Conservação como (BRASIL/MMA, 2011):

\begin{abstract}
espaço territorial e seus recursos ambientais, incluindo as águas jurisdicionais, com características naturais relevantes, legalmente instituído pelo Poder Público, com objetivos de conservação e limites definidos, sob regime especial de administração, ao qual se aplicam garantias adequadas de proteção.
\end{abstract}

O SNUC constitui-se de UCs federais, estaduais e municipais. As unidades integrantes dividem-se em dois grupos, com características específicas: Unidades de Proteção Integral e Unidades de Uso Sustentável. O objetivo básico das Unidades de Proteção Integral é preservar a natureza, sendo admitido apenas o uso indireto dos seus recursos naturais, com exceção dos casos previstos na lei. O objetivo básico das Unidades de Uso Sustentável é compatibilizar a conservação da natureza com o uso sustentável de parcela dos seus recursos naturais.

O grupo das Unidades de Proteção Integral é composto pelas seguintes categorias: Estação Ecológica, Reserva Biológica, Parque Nacional, Monumento Natural e Refúgio de Vida Silvestre. Já o grupo das Unidades de Uso Sustentável é composto por: Área de Proteção Ambiental - APP, Área de Relevante Interesse Ecológico - Arie, Florestas (nacionais ou estaduais), Reserva Extrativista - Resex, Reserva de Fauna, Reserva de Desenvolvimento Sustentável - RDS e Reserva Particular do Patrimônio Natural - RPPN (BRASIL/MMA, 2011).

A conservação da diversidade biológica depende do uso sustentável dos diversos habitats. A criação de UCs, especificamente na Amazônia, tem se mostrado uma ferramenta indispensável para se alcançar esse objetivo, na medida em que contribui para a gestão ambiental do território protegendo os patrimônios natural e cultural. Outro benefício é a proteção de diversos bens e serviços ambientais.

Passold e Kinker (2010) acreditam que, para que essas áreas sejam 
implementadas de fato e alcancem os objetivos para os quais foram criadas, muitos desafios devem ser superados, dentre os quais aproximar a sociedade das UCs. É preciso que a sociedade perceba a importância desses espaços, seus inúmeros benefícios e seja fiscalizadora das ações. Por outro lado, não há como alcançar os objetivos sem haver uma garantia de sustentabilidade econômica das áreas protegidas. Uma fiscalização eficiente dos cidadãos deve possibilitar que os recursos financeiros sejam ampliados e aplicados adequadamente.

Mesmo diante dos vários mecanismos, alguns deles instituídos por lei, visando garantir recursos financeiros para a manutenção dessas áreas como a compensação ambiental e a concessão de serviços -, a dependência financeira do setor público ainda é muito forte. Como as áreas naturais protegidas possuem grande potencial de fornecer serviços ecossistêmicos, o desafio que se apresenta sinaliza para algumas soluções quanto as possíveis contrapartidas financeiras e, dentre elas, estão os sistemas de pagamento por serviços ecossistêmicos como uma das principais opções.

Para Geluda e Young (2005), a lei do SNUC estabeleceu alguns instrumentos que visam o fortalecimento da gestão das UCs no intuito de reverter o quadro de precariedade da maioria delas. Dentre esses instrumentos, para os mesmos autores, existem aqueles que podem ser enquadrados como pagamentos por serviços ecossistêmicos. O primeiro deles está presente no art. 33:

Art. 33 - A exploração comercial de produtos, subprodutos ou serviços obtidos ou desenvolvidos a partir dos recursos naturais, biológicos, cênicos ou culturais ou da exploração da imagem de unidade de conservação, exceto Área de Proteção Ambiental e Reserva Particular do Patrimônio Natural, dependerá de prévia autorização e sujeitará o explorador a pagamento, conforme disposto em regulamento (BRASIL, 2000).

De forma simplificada, um esquema de pagamentos por serviços ecossistêmicos representaria o pagamento em troca de um serviço prestado pelo ecossistema. "Para viabilizar esta troca, é necessário criar mecanismos que permitam que os benefícios obtidos por esses serviços se transformem em uma demanda real" (WUNDER, et. al., 2010). 
Nesse contexto de serviços, podem ser encontradas duas perspectivas paralelas: a da economia ambiental e a da economia ecológica, que tendem a se aproximar em busca de resposta mais sustentáveis na relação sociedadeambiente. A economia ambiental utiliza mais comumente o termo serviço ambiental, priorizando a eficiência econômica e tentando forçar serviços dos ecossistemas no modelo de mercado. Para a economia ecológica, os serviços ecossistêmicos são os benefícios diretos e indiretos obtidos pelo homem a partir dos ecossistemas. De acordo com Andrade e Romeiro (2009: 9),

de modo geral, uma função ecossistêmica gera um determinado serviço ecossistêmico quando os processos naturais subjacentes desencadeiam uma série de benefícios direta ou indiretamente apropriáveis pelo ser humano, incorporando a noção de utilidade antropocêntrica.

A abordagem de serviços ecossistêmicos incide sobre os múltiplos objetivos da sustentabilidade ecológica, não somente com enfoque na distribuição e eficiência econômica. Farley e Constanza (2010) consideram que essa perspectiva favorece uma variedade de pagamentos e mecanismos, tanto de mercado quanto não mercantis.

No caso do turismo, o enfoque é dado às funções de informação, que se relacionam à capacidade de os ecossistemas naturais contribuírem para a manutenção da saúde humana, fornecendo oportunidades de reflexão, enriquecimento espiritual, desenvolvimento cognitivo, recreação e experiência estética (DE GROOT et. al., 2002 apud ANDRADE e ROMEIRO, 2009). Nessa categoria incluem-se conhecimento estético, recreação e (eco)turismo, inspiração cultural e artística, informações histórica, cultural e científica. "Essas funções são profundamente ligadas aos valores humanos, o que muitas vezes dificulta a sua correta definição e avaliação" (ANDRADE e ROMEIRO, 2009: 12).

A visitação pública, entendida aqui como a possibilidade de desenvolver o segmento turístico nas áreas protegidas, trata-se de uma estratégia que pode ser mais estimulada, objetivando potencializar os benefícios do turismo. Além disso, o turismo em áreas protegidas deve ter o planejamento como elementochave para que os impactos que o ambiente possa sofrer sejam minimizados. É necessário pensar também que o objetivo do desenvolvimento turístico é 
promover uma atividade que não venha a comprometer a implementação de outros planos, programas ou projetos.

Importa destacar que no Brasil são adotadas várias terminologias referentes à realização de atividades nas UCs, sejam com fins educacionais, recreativos, culturais ou outros: ecoturismo, turismo ecológico, visitação em UCs, uso público em UCs, turismo em áreas naturais, educação ambiental etc. Estes são os termos mais usuais e presentes em instrumentos legais nas três esferas de governo (PASSOLD e KINKER, 2010).

Em uma tentativa de sistematizar melhor o estudo, utilizar-se-á o termo turismo e uma de suas segmentações, o ecoturismo, por ocorrer em áreas protegidas ou com pouca intervenção humana. O termo uso público também será o mais utilizado, como sinônimo de visitação em UCs. É interessante notar que os Estados amazônicos perseguem diversas estratégicas para consolidar o povoamento e alcançar o desenvolvimento sustentável, dentre elas destaca-se o ecoturismo, incluído como uma atividade básica (BECKER, 2009).

Um dos objetivos principais de criação das áreas protegidas é a conservação da natureza, por esse motivo o uso público em cada categoria é diferente. Nesse sentido, o poder público passa a efetivar o planejamento ambiental, incluindo o turismo como um fator de desenvolvimento local.

A prova disso é que a Lei Geral do Turismo n. ${ }^{\circ} 11.771$, de 17 de setembro de 2008, dispõe sobre a Política Nacional de Turismo (BRASIL/MTur, 2011) e estabelece no art. 5. ${ }^{\circ}$ que um dos seus objetivos é "propiciar a prática de turismo sustentável nas áreas naturais, promovendo a atividade como veículo de educação e interpretação ambiental e incentivando a adoção de condutas e práticas de mínimo impacto compatíveis com a conservação do meio ambiente natural".

A lei geral esclarece ainda no parágrafo único do mesmo artigo que "quando se tratar de unidades de conservação, o turismo será desenvolvido em consonância com seus objetivos de criação e com o disposto no plano de manejo da unidade". No entanto, sabe-se que a implementação dos planos de manejo nas UCs, especialmente na Amazônia, ainda é um desafio a ser transposto. 


\section{Dificuldades e desafios do turismo em áreas protegidas}

Há um relativo consenso na comunidade científica de que os serviços ecossistêmicos de provisão (alimento, água e matéria-prima) podem contribuir para reduzir a pobreza e combater a fome. Para o alcance desses objetivos fazse necessário valorar economicamente os serviços fornecidos pela natureza.

Pelo fato de muitos desses serviços estarem disponíveis gratuitamente, sem mercado e sem preços atribuídos, o seu verdadeiro valor não foi incluído nas estimativas econômicas da sociedade (UNIÃO EUROPEIA, 2010). No entanto, não se pode pensar apenas em uma abordagem reducionista, desconsiderando outras fontes de valores, ao se considerar apenas a dimensão econômica. É fundamental sinalizar que "existem várias dimensões de valores dos serviços ecossistêmicos e que elas deveriam ser levadas em conta no processo de elaboração de políticas públicas e de tomada de decisão envolvendo o uso dos ecossistemas" (ANDRADE e ROMEIRO, 2009: 22).

Os pagamentos por serviços, sob a denominação ambientais (PSAs) ou ecossistêmicos (PSEs), estão sendo discutidos em âmbito global, tendo sido apontados como promissores instrumentos para gestão ambiental em diferentes escalas. Para Wunder (apud FARLEY e CONSTANZA, 2010), os regimes privados de pagamentos são mais eficazes do que os do setor público e associada a essa abordagem surge a concepção de que se deve priorizar eficiência sobre a redução da pobreza (PAGIOLA et. al., 2005; WUNDER, 2008 apud FARLEY e CONSTANZA, 2010):

PSE foi projetado para internalizar os benefícios que estão atualmente exteriorizados, trazendo custos marginais em maior alinhamento com benefícios marginais e crescente excedente econômico. Usando PSE esquemas para aliviar a pobreza também podem reduzir o excedente econômico e o futuro da escala do PSE. A sabedoria econômica convencional é que redução da maior pobreza poderia ser alcançada através da redistribuição de um maior excedente econômico (p. 2.066).

Nos esquemas baseados em pagamentos por serviços ecossistêmicos, comumente o turismo ganha destaque. Considerado como um produto 
verde, o segmento ecoturismo é um dos que mais cresce no mundo, com um aumento de gastos globais estimado em 20\% ao ano (TIES, 2006 apud TEEB, 2010). No Brasil, os estudos sobre o ecoturismo ganharam espaço na década de 80 do século 20, e desde então a atividade tem crescido em todo território, especialmente por conta da diversidade faunística, florística e cultural existentes.

Para Faco e Neiman (2010), em todas as definições existentes para o termo ecoturismo, três características estão sempre presentes e constituemse no tripé da sustentabilidade dessa atividade: a garantia de conservação ambiental, a educação ambiental e os benefícios às comunidades receptoras. A atividade ganhou tanta importância que com o objetivo de embasar a implementação de uma política nacional, em 1994 elaborou-se em nível federal o documento Diretrizes para uma Politica Nacional de Ecoturismo. Infelizmente, ele não saiu do papel.

Giraldella e Neiman (2010) contribuem com essa discussão ressaltando que o crescimento do turismo nas UCs no país, entre outros fatores, se deve a melhores salários da população, maiores períodos de férias, o acesso às áreas mais afastadas pela facilidade dos meios de transporte e, principalmente, pelo destaque que as áreas naturais ganharam nos últimos anos, após a provação do SNUC. Os dados gerados de visitação em UCs, porém, são pontuais e com informações insuficientes, sem o devido tratamento e sistematização.

Diante desse quadro, é possível inferir que o controle e o ordenamento dessas áreas ainda deixam a desejar. Dias (2003) considera que ainda há muito a se fazer para desenvolver o turismo em UCs, haja vista as inúmeras dificuldades encontradas. Os planos de manejo, por exemplo, deveriam ser constantemente revisados e para muitas áreas a não existência de um plano dificulta sua gestão e, certamente, o correto desenvolvimento do turismo. Os parcos investimentos do setor público também se tornam entraves ao desenvolvimento dessas áreas, bem como a capacitação, muitas vezes insuficiente, dos profissionais para atender às necessidades demandadas por uma UC, que especialmente na Amazônia são uma realidade singular em termos de acesso, transporte etc. Sem esquecer a precariedade ou a ausência de infraestrutura adequada para atender minimamente as necessidades operacionais da UC.

Por outro lado, de forma geral, é necessário considerar vários fatores que podem contribuir para um aumento da visitação nas UCs: a melhoria na 
eficiência da gestão participativa; mais estudos e manejo visando à conservação dos recursos; a implementação de sistemas de monitoramento de impactos de visitantes; a instalação de equipamentos facilitadores para as atividades de visitação e outros.

Como se pode observar, são muitos os desafios a serem superados, ainda há aqueles relacionados à proteção das espécies, à disposição de resíduos, às atividades produtivas e à participação das comunidades, tanto de dentro dos limites quanto do entorno das áreas protegidas, no ecoturismo. Deve-se ressaltar ainda a má administração dessas áreas, a falta de pessoal especializado e parcerias malfeitas, sem contar que o Brasil, em se tratando de concorrência, perde para países como Costa Rica e Peru, por sua deficiente ou precária infraestrutura de apoio à visitação.

Para que o turismo se mostre um elemento capaz de contribuir para o desenvolvimento local, fazem-se necessários estudos de áreas e das possibilidades de seu desenvolvimento, ou seja, investimento em pesquisas para se conhecer melhor o ambiente.

Abramovay (2010: 104) destaca a existência de promissores mercados voltados à valorização dos serviços ecossistêmicos prestados pelas florestas, dentre eles está a exploração das belezas naturais, ou seja, o turismo que, ao mesmo tempo, "pode contribuir de maneira decisiva tanto para a resiliência dos ecossistemas como na luta contra a pobreza". O turismo, definitivamente, precisa ser melhor compreendido e estudado.

$\mathrm{Na}$ perspectiva do TEEB (2010), se os pagamentos por serviços ecossistêmicos forem bem geridos, o turismo de pequena escala e de gestão externa de alta qualidade pode beneficiar as partes locais interessadas. Mas será que isso é possível?

Um outro foco de estudo dos territórios, que vem sendo desenvolvido na perspectiva do turismo, para além dos turistas, são as comunidades receptoras, os sujeitos que dão suporte para que o turismo aconteça. Eles são afetados sobremaneira, de diversas formas, e não devem ser esquecidos em nenhum nível de planejamento. De fato, a participação desses sujeitos determina o sucesso ou não do empreendimento turístico em qualquer território. Faz-se necessário a implementação de planejamentos participativos que deem voz e vez a esses sujeitos sociais, configurando-se como protagonistas da atividade.

Não é suficiente apenas gerir bem ou pensar em baixa escala, quando 
o (eco)turismo é conduzido apenas em função dos benefícios econômicos, paisagem, ambiente, identidade local, todos podem sofrer danos irreversíveis, pois ele não respeita fronteiras ou limites territoriais.

Infere-se ainda que a participação da comunidade é de grande valor em qualquer projeto que envolva o turismo, especialmente o ecoturismo, que dentre seus objetivos visa a melhoria da qualidade de vida da população envolvida com a atividade. $O$ ecoturismo pode ser uma forma de se atender aos princípios da sustentabilidade no turismo, pois representa um meio efetivo de atrair melhorias para localidades com grande potencial natural, sendo também um poderoso instrumento para a conservação ambiental, a partir do momento em que se implementem técnicas de manejo turístico para monitorar as mudanças.

Um aspecto importante e bastante relevante, que consta no Relatório do TEEB (2010) sobre serviços ecossistêmicos e áreas protegidas, é que para aprimorar os benefícios locais auferidos pela conservação, é necessário haver conexão entre as áreas protegidas e as áreas vizinhas, com foco constante nos serviços ecossistêmicos. O relatório apresenta como exemplo as áreas protegidas marinhas, em Tubbataha (Filipinas) e Velondriake (Madagascar), que melhoraram a receita nas regiões vizinhas por meio da coordenação do uso dos diferentes serviços ecossistêmicos por conservacionistas, pescadores e operadores de turismo. No Brasil, especialmente no Estado do Amazonas, em termos de políticas públicas, também se atentou como estratégia aos esquemas de incentivos à manutenção dos serviços ecossistêmicos.

Os pagamentos por serviços ambientais (PSAs) têm sido bastante discutidos desde 2007, quando o Governo do Amazonas criou a Lei Estadual de Mudanças Climáticas, Conservação Ambiental e Desenvolvimento Sustentável (Lei n. ${ }^{\circ}$ 3.135), que estabeleceu sete programas operacionais estratégicos no foco de conservação ambiental, energia alternativa e educação sobre mudanças climáticas. É nesse contexto que o governo também criou o Centro Estadual de Mudanças Climáticas (Ceclima), visando implementar a Política Amazonense de Mudanças Climáticas (AMAZONAS, 2010).

Wunder (et. al., 2010) considera que um mal-entendido frequente é o de que PSAs requerem mercados para funcionar. Segundo ele, apenas para serviços relacionados ao carbono alguns mercados se desenvolveram e dependem de intermediação para concretizar-se. Não devem ser pensados dessa forma 
os usos diretos da biodiversidade como, por exemplo, a bioprospecção e o ecoturismo. Segundo o mesmo estudioso, esses serviços dependem de uma interação mais direta entre usuários específicos e provedores, assim novos mecanismos de pagamentos devem ser implementados.

Dessa forma, as áreas protegidas que desenvolvem o ecoturismo são potencialmente elegíveis para implementação de algumas modalidades de pagamentos por esses serviços. Geluda e Young (2005) consideram que o mecanismo de pagamentos por serviços ecossistêmicos (PSEs) previsto na lei do SNUC, que causará mais impacto, é a compensação ambiental prevista no artigo 36:

Art. 36 - Nos casos de licenciamento ambiental de empreendimentos de significativo impacto ambiental, assim considerado pelo órgão ambiental competente, com fundamento em estudo de impacto ambiental e respectivo relatório (...), o empreendedor é obrigado a apoiar a implantação e manutenção de unidade de conservação do Grupo de Proteção Integral (...).

Nesse caso específico,

Trata-se de um instrumento baseado sobretudo no princípio do 'poluidor-pagador'. Mas pode-se pensar que, depois da cobrança, os recursos são obrigatoriamente destinados para unidades de conservação como forma de compensar os impactos 'negativos, não mitigáveis' (Decreto n. ${ }^{\circ} 4.340$, art. 31). É um pagamento para manter os serviços gerais (e bens) prestados por áreas protegidas, como forma de compensar os bens e serviços ambientais degradados pelo empreendimento. Nesse ponto de vista, devido à vinculação feita, pode-se pensar a compensação como uma soma dos princípios do 'poluidor-pagador' e do 'provedor-recebedor' e encará-la como um PSE (GELUDA e YOUNG, 2005: 577).

Embora a regulamentação da implementação da compensação precise ficar mais clara na política ambiental brasileira, já é possível contar com alguns exemplos nas áreas protegidas do Brasil. Isso significa que há um 
grande potencial a ser explorado nesse mecanismo. Ele deve ser um aliado do orçamento público que obrigatoriamente inclua o fortalecimento do (eco) turismo nas UCs.

Com vistas a desenvolver uma atividade o mais sustentável possível, Leff (2010) oferece algumas contribuições para o turismo que, claramente, podem ser aplicadas às áreas protegidas.

Inicialmente, o estudioso afirma que é necessário internalizar os custos ambientais gerados pela atividade e, ao mesmo tempo, impedir que os megaprojetos turísticos interfiram, sobremaneira, nos processos ecológicos e poluam o entorno ambiental. Nesse sentido, a saída seria a ecologização do turismo, ou seja, reduzir a enorme quantidade de energia que gasta, buscar a utilização de energias renováveis, oferecer um destino melhor e um tratamento adequado para os resíduos, além de tratar e reduzir a quantidade de água utilizada.

A ecologização do turismo consistiria também em valorizar ainda mais atrativos naturais e culturais poluindo cada vez menos rios, oceanos, praias, seja em ambientes urbanos ou rurais. Mas isso tudo não é suficiente, o segmento deve investir na conservação de áreas naturais como manguezais, que são barreiras naturais contra intempéries, bem como outras infraestruturas de proteção civil e sistemas de alerta para prevenir ou evitar fenômenos meteorológicos. Alguns exemplos são a implementação de medidas no âmbito do ordenamento do território; regulação das áreas de risco ou da previsão de requalificação dessas áreas; a implementação de sistemas de alerta e aviso; sensibilização da população; elaboração de planos de emergência de proteção civil; ou a realização de exercícios e simulações.

Importa destacar nesse contexto que a artificialização da natureza também deve ser evitada, ou seja, a criação de "lugares" sem referência e sem identidade são paradigmas de insustentabilidade.

Outras contribuições de Leff (2010) dizem respeito à inclusão da avaliação de impacto ambiental para autorizar o funcionamento de empreendimentos turísticos (o que a legislação brasileira já prevê), com auditorias externas constantes. Ainda outra é optar pela participação local nos planos, programas e projetos, bem como requerer um maior envolvimento das autoridades locais com a questão. Leff propõe, finalmente, um imposto ecológico a ser aplicado em reflorestamento, restauração ecológica e proteção do ambiente natural: 
A empresa turística não deve ser uma indústria de enclaves para o usufruto do visitante estrangeiro, a que a população local só tem acesso como empregados do negócio turístico, em que se impõe um estilo arquitetônico e um modelo de vida globalizado alheio às culturas locais, onde dominam as línguas estrangeiras sobre o idioma nacional (LEFF, 2010: 155).

Nesse sentido, o (eco)turismo não pode continuar a gerar riscos e deixar vulneráveis os ambientes onde constrói sua infraestrutura e se estabelece, havendo a necessidade de ecologizar sua prática. Isso se aplica às UCS.

\section{Considerações finais}

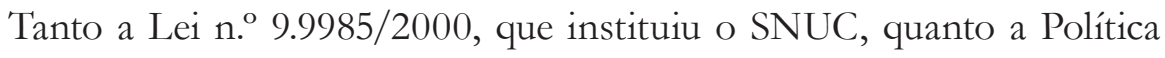
Nacional de Turismo dispõem, em alguns dos seus artigos, sobre a visitação em áreas protegidas e a incentivam. Nesse sentido, entende-se que a crescente demanda nas UCs brasileiras deveria gerar uma postura diferente nos gestores e no governo.

Uma nova postura seria no sentido de transformar o turismo nessas áreas em estratégica de gestão, com melhor aproveitamento das taxas de visita, por exemplo, para aplicação na manutenção da unidade, no desenvolvimento de uma política de recursos humanos capaz de atender às demandas da área e na consolidação ou implementação do plano de manejo em cada uma delas. O que implicaria em adotar uma legislação que dê autonomia e poder à gestão local.

É evidente que outras necessidades devem ser atendidas, como a consolidação de um sistema de informações, o oferecimento de uma infraestrutura adequada, a aplicação de metodologias para a avaliação de impactos e manejo de uso público e o fortalecimento de parcerias.

Continuar discutindo a compensação ambiental, a destinação, a distribuição dos recursos financeiros, o controle, a gestão da atividade e muitos outros pontos são igualmente necessário e urgente.

Mas não se pode esquecer que para o desenvolvimento do ecoturismo em UCs a gestão participativa também deve ser acionada, isso pode possibilitar 
que as responsabilidades sejam compartilhadas, assim a participação comunitária certamente será mais efetiva e pode garantir maior eficiência na gestão e nos assuntos que envolvam a proteção e o respeito da área por parte dos comunitários. Dessa forma, a exploração racional dos recursos ambientais e do turismo deve levar em consideração as comunidades locais não como objeto de consumo do turismo, mas como poderoso instrumento de base que merece respeito, e adotar o conceito de sustentabilidade nos debates é fundamental para situar qualquer experiência turística como alternativa viável de desenvolvimento.

Destaca-se que a saúde econômica, física, mental e cultural dos seres humanos depende da saúde dos ecossistemas, como já citado anteriormente, e da forma como vem se apresentando a relação sociedade-natureza e as negociações de PSE, muitas vezes atendendo somente a interesses específicos, a mercantilização dos serviços dos ecossistemas é indesejável.

Faz-se necessária mais cooperação entre as diversas iniciativas, bem como o desenvolvimento de mecanismos adequados no intuito de pagar pelos serviços dos ecossistemas.

Este estudo corrobora com as ideias de Farley e Constanza (2010), ao entender que os pagamentos devem priorizar a regulação do clima e gases na atmosfera, a prestação de água e alimentos, a biodiversidade que sustenta todos os outros serviços, uma vez que eles são serviços insubstituíveis. "Para esses recursos infinitamente valiosos, níveis de pagamento devem ser determinados pelos custos de fornecimento, e não por uma estimativa monetária dos benefícios" (p. 2.066).

Por fim, a lógica que deve ser repensada é a do espaço-mercadoria, com influência hegemônica de agentes externos visando o controle social e a padronização dos produtos e serviços turísticos, talvez pensar na ecologização seja apontar um caminho diferente para o futuro do (eco)turismo: aquele em que a natureza não seja tratada como mercadoria, a cultura seja respeitada e valorizada, bem como o espaço geográfico não seja mercantilizado. O turismo a ser desenvolvido nas UCs deve potencializar e privilegiar as iniciativas locais, como, por exemplo, estabelecer um contrato de gestão com os gestores locais por meio do qual eles possam cobrar, utilizar os recursos - e não os repassar à União, no caso de UCs nacionais - e tenham metas que possam ser fiscalizadas. 


\section{Referências}

ABRAMOVAY, Ricardo. Desenvolvimento sustentável: qual a estratégia para o Brasil? Novos estudos.Cebrap,São Paulo,n. ${ }^{\circ} 87, j u l ., 2010$. Disponívelem: < $\underline{\text { http:// }}$ www.scielo.br/scielo.php? pid $=$ S0101-33002010000200006\&script $=$ sci arttext> Acesso em: 13 jan 2010.

AMAZONAS. Governo do Estado. O valor dos serviços da natureza: subsídios para políticas públicas de serviços ambientais no Amazonas / Secretaria de Estado de Meio Ambiente e Desenvolvimento Sustentável. Manaus: SDS / Ceclima, 2010.

ANDRADE, Daniel Caixeta; ROMEIRO, Ademar Ribeiro. Serviços ecossistêmicos e sua importância para o sistema econômico e o bem-estar bumano. Disponível em: $<$ http:// www.eco.unicamp.br/docprod/downarq.php?id=1785\&tp=a $>\quad n$. 155, fev., 2009. IE/Unicamp. Acesso em: 7 jun 2012.

BECKER, Bertha K. Amazônia: geopolítica na virada do III milênio. Rio de Janeiro: Garamond, 2009.

BRASIL. Lei Geral do Turismo n. ${ }^{\circ}$ 11.771/08, de 17 de setembro de 2008. Dispõe sobre a Política Nacional de Turismo. Disponível em: < http://www. planalto.gov.br/ccivil_03/_ato2007-2010/2008/lei/111771.htm> Acesso em: 19 set 2011.

BRASIL. Lei n. .9 .985 , de 18 de julho de 2000. Institui o Sistema Nacional de Unidades de Conservação da Natureza, e dá outras providências. Disponível em: < http://www.planalto.gov.br/ccivil 03/leis/L9985.htm > Acesso em: 19 set 2011 .

COSTA, Patrícia Côrtes. Unidades de conservação: matéria-prima do ecoturismo. São Paulo: Aleph, 2002.

DIAS, Reinaldo. Turismo sustentável e meio ambiente. São Paulo: Atlas, 2003.

FACO, Regiane Avena; NEIMAN, Zysman. A natureza do ecoturismo: conceitos e segmentação. In: NEIMAN, Zysman; RABINOVICI, Andréa (Orgs.). Turismo e meio ambiente no Brasil. Barueri, SP: Manole, 2010.

FARLEY, Joshua; COSTANZA, Robert. Payments for ecosystem services: 
from local to global. Ecological Economics, 69 (2010)2.060-2.068.

GELUDA, L; YOUNG, C. E. F. Pagamentos por serviços ecossistêmicos previstos na lei do SNUC: teoria, potencialidades e relevância. III Simpósio de Áreas Protegidas: repensando escalas de atuação, 2005.

GIRALDELLA, Heloana; NEIMAN, Zysmam. Planejamento e gestão em áreas naturais protegidas. In: NEIMAN, Zysman; RABINOVICI, Andréa (Orgs.). Turismo e meio ambiente no Brasil. Barueri, SP: Manole, 2010.

LEFF, Enrique. Discursos sustentáveis. São Paulo: Cortez, 2010.

MILLENNIUM ECOSYSTEM ASSESSMENT (MA, 2003). Ecosystem and Human Well-Being: a framework for assessment. Washington, DC: Island Press, 2003.

PASSOLD, Anna Júlia; KINKER, Sônia Maria Sfair. Visitação sustentável em unidades de conservação. In: Gestão ambiental e sustentabilidade no turismo. PHILIPPI JÚNIOR, Arlindo; RUSCHMANN, Doris van de Meene (Eds.). Barueri, SP: Manole, 2010.

THE ECONOMICS OF ECOSYSTEMS AND BIODIVERSITY - TEEB. A Economia dos Ecossistemas e da Biodiversidade para Formuladores de Politicas Locais e Regionais, 2010.

UNIÃO EUROPEIA. Bens e Serviços Ecossistêmicos. Setembro de 2009.

WUNDER, Sven (Coord.);BÖRNER, Jan;TITO, Marcos Rügnitz; PEREIRA, Lígia. Pagamentos por serviços ambientais: perspectivas para a Amazônia Legal. Brasília: MMA, 2009. 